The Present Status and Prospect of Research on Rapid Freeze-drying

\title{
Food in China
}

Hua Li, Xingli Jiao, Longgang Geng

School of Chemical and Energy Engineering, Zhengzhou University, Zhengzhou 450001, China,

Email: lihua@zzu.edu.cn

School of Chemical and Energy Engineering, Zhengzhou University, Zhengzhou 450001, China,

Email: jiaoxingli123@163.com

School of Chemical and Energy Engineering, Zhengzhou University, Zhengzhou 450001, China,

Email: genglg10@163.com

\section{Abstract:}

The basic principles, process, features and present status of freeze-dried food were introduced in this paper, in which the main problems of the freeze-dried food in our country were proposed, and its main development trend was also analyzed.

Keyword: vacuum freeze-drying, food, present status, problem

\section{Council for Innovative Research}

Peer Review Research Publishing System

\section{Journal: Journal of Advances in Chemistry}

Vol 1, No. 1

editor@cirworld.com 
With the improvement of the living standard, people's requirements on food qualitatively changed as well. The modern consumers also pursue "nature, nutrition, safety, health, and convenience" besides color, smell and taste. Vacuum freeze-dried food is well matched with the three development trends of "green food", "convenient food" and "health food". The development of freeze-dried food is not only the need of the sack industry, but also the new development direction of food in 21 st century in our country.

\section{The developing history and the present conditions of freeze-dried food}

The first culture known to practice freeze drying was the Incas. In the 15th century, crops were stored in the high altitudes of the Andes. This caused the foods to freeze while the water vaporized due to the low air pressure. During the early 20th century, a number of independent inventors created vacuum technology that made freeze drying possible. The most successful of these was S.F. Shackell, who began to utilize it on bodily fluids as of 1909 , this new technology was firstly used in the pharmaceutical industry in America until 1943. And later in 60's some countries in Western Europe, such as Germany and Netherlands, began to use this technology in food industry. Subsequently, Japan, America, UK, Hong Kong, Taiwan and some other developed countries and regions successively established freeze-dried food plants, which have reached the level of industrial production at present ${ }^{1-7}$.

Freeze-dried food also started early in China. Its application in food processing was studied from 50's and substantial achievement had been made since its origination. In 70's, some test and production bases were established in Beijing, Dalian, and Shanghai. But these bases had been demolished owing to lack of market competition ability. With the development of food industry in China and the demands on freeze-dried food in the international and domestic markets, people had further understanding about its outstanding characteristic of convenience, health, nutrition, hygiene, and good storage, as well as a series of experimental researches on this technology and equipments had been successfully carried out. At present, Ningxia, Shenzhen, Tianjin, Henan, Hebei, Liaoning, Shanghai, Shandong, Jiangsu have developed freeze-drying equipments, and started producing freeze-dried food. What's more, some production lines have been introduced into Qingdao, Guangdong, Fujian, Beijing, and Xinjiang from abroad, to produce freeze-dried food such as condiment and vegetable protein, which achieved great economic benefits.

Generally speaking, a tremendous amount of scientific researches on freeze-drying technology and equipment in our country had been done from 70's to 80's, but was only restricted to scientific experiment. Until 90's, great progress have been achieved in freeze-drying technology. At present, in Xinjiang, Ningxia, Henan, Hebei and Shandong, a batch of freeze-dried food factories have been built or are being built, which marks lyophilization food market is starting in China.

\section{The characteristics, problems and countermeasures of freeze-dried food}

\subsection{Principles}

The freeze-drying, is the use of sublimation principle, work is under vacuum pressure, so that the primary freeze of the material in the water, without ice melting, ice sublimate directly into gas in the vacuum distillation of the state to go off, vacuum freeze-drying products was able to ensure food protein, vitamins and other nutrients, especially those who are not volatile loss of heat-sensitive components, and maximize their original nutrients, and can inhibit the harmful effects of bacteria and enzymes to effectively prevent the drying process of oxidation.

\subsection{The technical process of freeze-drying food ${ }^{8,9}$}

\subsubsection{Pretreatment}

The decision to pretreatment a product is based on theoretical knowledge of freeze-drying and its requirements, or is demanded by cycle time or product quality considerations. Methods of pretreatment include: selection, cleaning, slicing, 
heat blanching, sterilizing, freeze concentration, solution phase concentration, formulation to preserve product appearance, formulation to increase the surface area, and decreasing high vapor pressure solvents, etc. Freeze-dried food with high quality can be produced only by doing all the trivial thing of pretreatment excellently.

\subsubsection{Quick-freezing, solidification}

The food of pretreatment was freezed quickly, the quicker the freeze-drying, the smaller the crystallization in the food, the tissue structure destruction of food is smaller.

\subsubsection{Sublimation drying}

Sublimation drying is also called the primary drying. During the primary drying phase, the pressure is lowered (to the range of a few millibars), and enough heat is supplied to the material for the water to sublime. The amount of heat necessary can be calculated using the sublimating molecules' latent heat of sublimation. In this initial drying phase, about $95 \%$ of the water in the material is sublimated. This phase may be slow (can be several days in the industry), because, if too much heat is added, the material's structure could be altered. In this phase, pressure is controlled through the application of partial vacuum. The vacuum speeds up the sublimation, making it useful as a deliberate drying process. Furthermore, a cold condenser chamber or condenser plates provide a surface for the water vapor to re-solidify on. This condenser plays no role in keeping the material frozen; rather, it prevents water vapor from reaching the vacuum pump, which could degrade the pump's performance. Condenser temperatures are typically below $-50{ }^{\circ} \mathrm{C}\left(-60^{\circ} \mathrm{F}\right)$. It is important to note that, in this range of pressure, the heat is brought mainly by conduction or radiation; the convection effect is negligible, due to the low air density.

\subsubsection{Desorption drying}

Desorption drying, also named the secondary drying, the secondary drying phase aims to remove unfrozen water molecules, since the ice was removed in the primary drying phase. This part of the freeze-drying process is governed by the material's adsorption isotherms. In this phase, the temperature is raised higher than in the primary drying phase, and can even be above $0{ }^{\circ} \mathrm{C}$, to break any physic-chemical interactions that have formed between the water molecules and the frozen material. Usually the pressure is also lowered in this stage to encourage desorption (typically in the range of microbars, or fractions of a pascal). However, there are products that benefit from increased pressure as well.

At the end of the operation, the final residual water content in the product is extremely low, around $1 \%$ to $5 \%$.

\subsubsection{The treatment after freezing}

The main process after freezing-drying is packaging. After the freeze-drying process is complete, the vacuum is usually broken with an inert gas, such as nitrogen, before the material is sealed. As the packaging of the freezing-dried food, good sealing, shading and certain repellency are needed.

\subsection{Kinds of freezing-dried food ${ }^{10-15}$}

Almost all of the food material, fruits, vegetables, meat, eggs, and seafood can be processed by vacuum freeze-drying. However, the cost of vacuum freeze-drying is high, therefore limited for high value added products. Kinds of vacuum freeze-dried food are as followings:

(1) the convenient foods: instant noodles and its auxiliary materials, meatball, soup sticks, etc.

(2) fruits: apple, pear, peach, apricot, banana, strawberry, red jujube, pineapple, cantaloupe, longan, durian, blueberry, mangosteen, etc.

(3) vegetables: shallot, ginger, garlic, carrot, chili pepper, onion, carrot, green pepper, spinach, cauliflower, snow bean, asparagus, string beans, parsley, broccoli, edible fungus, etc. 
(4) meat: pork, chicken, beef, mutton, snake flesh, etc..

(5) aquatic products: squid, fillet, shrimp, crab meat, cuttlefish, whitebait, etc.

(6) instant beverages: coffee, soya-bean milk, milk, juice, royal jelly, etc..

(7) pharmaceutical products: angelica, rhubarb, deer antlers, deer blood, earthworm, scorpion, woodlouse, ginseng, codonopsis pilosula, and health-carefood, etc.

(8) flavourings: all kinds of spices used in cooking.

\subsection{Characteristics of the freeze-drying food $16,17,18$}

Since the freeze-drying process is under low pressure at low temperatures, protein and vitamins and other nutrients remain basically unchanged, the inherent property of material remains basically no loss, so the vacuum freeze-drying technique has a number of advantages over alternative stabilizing methods. (1) the freeze-drying is under high vacuum, very little oxygen, therefore inhibits the action of microorganisms and enzymes that would normally spoil or degrade the substance. (2) the freeze-drying is under low pressure, dry material was not oxidized. (3) the freeze-drying is at low temperature, the material in the heat-sensitive components easy to play without denaturation or loss of energy. (4) the freeze-dried material can form a "skeleton" to keep original shape after drying, shrinkage does not occur, and the internal structure was loose, porous sponge. (5) dehydration is complete because the freeze-drying can remove about $90 \%$ to $95 \%$ water, the freeze-dried food can be long-term preservation and easy to transport because of the weight light.

\subsection{The market of freeze-drying food}

Freeze-dried food has many advantages over ordinary food, therefore, it becomes popular quickly in Japanese, European and American markets. Not only freeze-dried fruits, vegetables, meat, and aquatic products were passed into both home and restaurants, but also they were also used in many special industries such as military, astronavigation, mountaineering, tour, exploration, mining, navigation, and investigation in the Arctic and Antarctic. As dehydrated food in Japanese market, freeze-dried food is more than 7 billion bags. In the United States, half of all the coffee and tea factories use freeze-drying product, and freeze-dried food account for $40 \%-50 \%$ of the convenient food; While in Europe, freeze-dried coffee accounts for $40 \%-70 \%$ of all instant coffee; Hong Kong, Singapore and South Korea import freeze-dried food from abroad about 50 billion yen each year, therefore, freeze-dried food is gradually becoming the bulk commodity of international trade.

\subsection{The problems and countermeasures of freeze-dried food ${ }^{9,19,20}$}

(1) Freeze-drying is needs to operate under the high vacuum and at low temperature; therefore the cost of the freeze-dried food is high. The price of freeze-dried food is 4-6 times than hot-air dried food in international market.

(2) The freeze-dried food easily absorbs moisture and rancidity once exposed to the air.

(3) Freeze-dried food is porous and loose, thus is easily broken or powdered during transportation and sales process.

(4) The investment cost of the freeze-drying is relatively high, the main reason for high cost is the need to operate under a vacuum and at low temperature.

(5) Different freeze-dried foods have different technologies, therefore the lyophilization curve must be tested by the measurement of the melting point, thermal conductivity, and the optimal technological condition can be find out only by the experiment of lyophilization curve.

Based on the above-mentioned, some methods can be considered as follows:

(1) Select reasonable material, to increase its additional value and reduce the ratio of energy consumption. If the material 
has high quality, special nutrition and high additional value, then the superiority of the freeze-dried food in quality, level, and price will be outstanding.

(2) Improve the equipment of freeze-drying by shortening the drying time to reduce the energy consumption.

(3) Improve process of freeze-drying, by shortening time to reduce the energy consumption. As to different materials and pretreatments, the reasonable temperature of heating plate, pressure of freeze-drying chamber and food thickness can be selected correctly.

(4) Improve the technology of freeze-drying. Introducing new technology such as the adsorption freeze-drying etc., and shortening the time of sublimation to reduce the energy consumption of freeze-drying and improve the product quality.

\section{The prospect and outlook}

China is a large agricultural country with rich vegetables, meat and aquatic product. If these food were developed to dried products with the highest quality by freeze-drying technology, such as freeze-dried vegetables and meat, it will be bring huge economic benefits.

With global environment deterioration, clean and green food becomes more and more welcome, green food becomes the main tendency in food industry. With the rapid tempo of modern life, people require more and more fast food, thus the convenient food become the another trend in the development of food industry. With the increasing incidence of hyperlipidemia, hypertension, diabete, and cardiovascular or cerebrovascular disease, health food with low calorie or low fat became another development trend. Freeze-drying technology suits the three development tendencies: "green food", "convenient food" and "health food" well. We should actively develop the freeze-dried food to satisfy the growing needs of the new food material, the development of freeze-drying techniques are indispensable. Therefore, food vacuum freeze-drying technology will become an important application of 21 st century technology.

\section{References}

[1] Oikonomopoulou,V. P., Krokida, M. K., Karathanos, V. T. Procedia 2011. Food Science, 1, 647.

[2] Hua, Z. Z., Li, Y. F., Liu, B. L. 2005. The Principle and Equipment of Food Refrigerated. Beijing: Mechanical Industry Press.

[3] Fennema, O. R. 1996. Food Chemistry. The 3rd Edition. New York: Marcel Dekker Inc.

[4] Blanshard, J. M. V., Lillford, P. J. 1993. The Glassy State in Foods. England: Nottingham University Press.

[5] Xu, C. H., Zhang, S. W., Guan, K.Z. 2004. Vacuum Drying. Beijing: Chemical Industry Press.

[6] Chi, S. S., Nam, J. H., Kim, C. J., Ro, S.T. 2005. Journal of Food Engineering, 67, 467.

[7] Hua, Z. Z., Ren, H.S. 1994. Biomedical Technology at Low Temperature. Beijing: Science Press.

[8] Xiao, X., Ren, L., Zhang, D. H. 2008. Technology and Equipment. 7, 26.

[9] Hua, Z. Z. 2005. Vacuum Freeze-Drying Technology. Beijing: Science Press.

[10] Tong, J. M., Ma, W. L. 2001. Light Machinery Industry, 4, 5.

[11] Anwar, S. H., Kunz, Benno. 2011. Journal of Food Engineering, 105, 367.

[12] Corrêa, S.C., Clerici, M.T.P.S., Garcia, J.S., Ferreira, E.B., Eberlin, M.N., Azevedo, L. 2011. Food Research International. 44, 2385.

[13] Anwar, S. H., Kunz, Benno. 2011. Journal of Food Engineering. 105, 367.

[14] Fu, N., Chen, X. D. 2011. Food Research International, 44, 1127. 
[15] Caparino, O. A., Tang, J., Nindo, C. I., Sablani, S. S., Powers, J. R., Fellman, J. K. 2012. Journal of Food Engineering. $111,135$.

[16] Mrad, N. D., Boudhrioua, N., Kechaou, N., Courtois, F., Bonazzi, C. 2012. Food and Bioproducts Processing. 90, 433.

[17] Kong, F. Z. Packaging and Food Machinery, 2001, 38, 28.

[18] Zhu, K. Q., Lv, S. F. 2010. Food Processing. 35, 46.

[19]. Sansiribhan, S., Devahastin, S., Soponronnarit, S. 2012. Journal of Food Engineering. 109, 148.

[20] León-Martínez, F.M., Rodríguez-Ramírez, J., Medina-Torres, L.L., Méndez Lagunas, L.L., Bernad-Bernad, M.J.2011. Carbohydrate Polymers. 84, 439. 